Mongolian Academy of Sciences
Mongolian Journal of Chemistry
Institute of Chemistry \& Chemical Technology

\title{
Alkaloids from cultivated plant of Peganum harmala $\mathrm{L}$
}

\author{
S. Javzan', D. Selenge ${ }^{1}$, Y. Jamyansan ${ }^{1}$, \\ J. Nadmid ${ }^{2}$, Yu Ouynbileg ${ }^{3}$ \\ 1. Institute of Chemistry and Chemical Techology, Mongolian \\ Academy of Sciences, Ulaanbaatar 51, Mongolia \\ ${ }^{2}$ Mongolian University of Science and Technology, School of Materials Technology \\ ${ }^{3}$ Institute of Biology, Mongolian Academy of Sciences, Ulaanbaatar 51, Mongolia
}

\begin{abstract}
Alkaloids such as 1H-cyclopenta(b) quinoline, 2.3.5.6.7.8-hexahydro-9-amino-; Vasicinone(1H-Pyrrolo[2.1-b]quinazolin-9-one,3-hydroxy-2.3-dihydro) and harmine were isolated from cultivated plant of $P$. harmala. Four unknown alkaloids were isolated from $P$. harmala for the first time: 2.2.6.6-Tetramethyl-4-piperidone., Quinoline, 2.3.4-trimethyl-., Pyridine, 2-phenoxy-4amino- and 4-(3-Propynyloxy)- quinazoline. Their structures were determined by GC-MS.
\end{abstract}

Keywords: GC-MS, alkaloids, harmine, Peganum, Zygophyllaceae

\section{Introduction}

7 he genus Peganum (Zygophyllaceae) comprises 6 species, that are widely distributed in Northern America, Mediterranean regian, Russia and Mongolia. There were found 3 species- Peganum nigellastrum Bunge, Peganum harmala $L$ and Peganum multisectum Maxim in Mongolia[1]. One of them- Peganum harmala (P.harmala) is commonly found in the Dzungarian Gobi, Transaltai Gobi, Depression of Great lakes, Valley of Lakes, Mongolian Altai and Gobi [2]. This plant has been used as a Chinese traditional medicine against a rheumatism, an abscess, an inflammation and so on[3]. In traditional Mongolian medicine it is used as antitussive and antidote and it also eliminates yellow liquorstasis[4]. At the same time, $P$. harmala is well-known traditional herbal medicine in China and Asian countries for the treatment of a variety of human ailments[5] and skin diseases[6]. Its seeds showed narcotic, anthelmintic and antispasmodic effects and have been employed in the cases of asthma and rhematism treatments [7]. Many components such as alkaloids, flavonoids, stroides and amino acids have been isolated from $P$. harmala [8-10]. The $\beta$-carboline type alkaloids-harmine and harmaline were discovered in P.harmala and are well known as a central nervous system(CNS) stumlant [11] and hypotensive substances, antispasmolitic, antihistaminic, vasorelaxant, antibacterial, sedative effects, cytotoxic, antivirus activities and narcotic effect (vasicinone) [12-13]. Thus, the alkaliod fractions of three plants of the genus Peganum showed anti-tumor activity. Previously, alkaloids, (+-)-vasicinone, 6hydroxy-6.8.9.11-tetrahydro[2.1-

b]quinazolin-11-one, (+-)-vasicine, (+-)vasicinolone, deoxyvasicinone, 6.7.8.9tetrahydro-pyrido[2.1-b] quinozolin-11-one, peganine, tetrahydroharmine, harmaline, harmine, harmalol, harmol[14-15], dipegine, dipeginol[16] and desoxypeganine[17] were 
isolated and identified from seeds, aerial parts and roots of $P$. harmala.

Previous research on P.harmala were performed by using naturally grown plants. However, there is a risk on study of naturally grown plants because of natural climate changes and human activity. Therefore, cultivation of the naturally grown plants became popular around the world.

The goal of the present study was to characterise alkaloids from cultivated P.harmala and compare them with the alkaloids of naturally grown plants.

\section{Experimental}

Plant material: The ground aerial parts and roots of Peganum harmala $L$ were collected in july 2009 from greenhouse of the Institute of Botany, Mongolian Academy of Sciences.

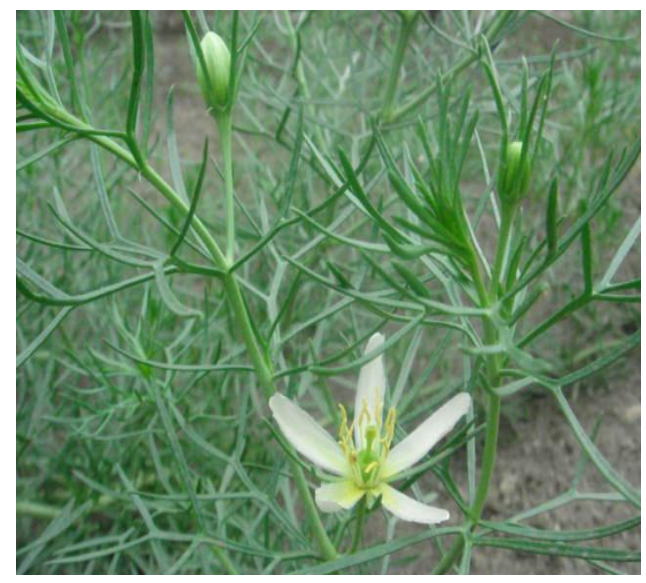

Planted Peganum harmala L

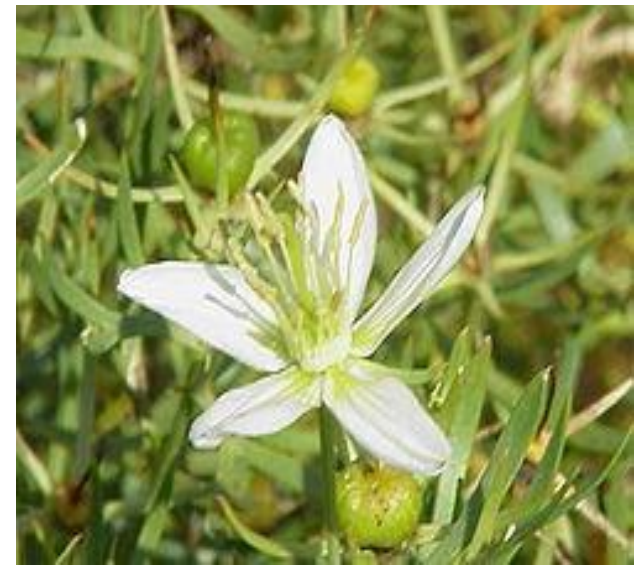

Natural Peganum harmala L

\section{Experimental:}

The air dried under aerial parts and roots (33.5 and 8.6g) was extracted with 95\% ethanol at room temperature. Following the evaporation of the solvent in vacuo the residue was suspended in 5\% $\mathrm{HCI}$ at $\mathrm{pH} \mathrm{1-2}$ and extracted with hexane(non-alkaloid). This purified acidic solution was made alkaline with $25 \% \mathrm{NH}_{4} \mathrm{OH}$ to $\mathrm{pH}-9-10$ and extracted with $\mathrm{CHCI}_{3}$. The combined $\mathrm{CHCI}_{3}$ extracts were dried (anh. $\left.\mathrm{Na}_{2} \mathrm{SO}_{4}\right)$ then concentrated to give crude alkaloids $1.1714 \mathrm{~g}$ of aerial parts $(3.4 \%)$ and $0.2136 \mathrm{~g} \operatorname{roots}(13.29 \% /)$.

Gas chromatography-Mass spectrometry () (GC-MS), $\mathrm{K}$ equipped with fused silica capillary column $30 \mathrm{mX} 0.25 \mathrm{mmX} 0.25 \mu \mathrm{m}$ was used. Coated with HP-5 MS phase and coupled with Hewlett Packard 6890/MSD 5793A E was used. Carrying gas was :He, $0.8 \mathrm{ml} / \mathrm{min}$. Program of the GC-MS as follows: temperature $50-300^{\circ} \mathrm{C}$ at $6^{\circ} / \mathrm{min}$, isotherm 0-10 $\mathrm{min}$, solvent delay $2.0 \mathrm{~min}$, mas range 50-750. The flame ionization detector was used at $\mathrm{T}_{\text {inl }} 260^{\circ} \mathrm{C}, \mathrm{T}_{\text {aux }} 280^{\circ} \mathrm{C}$.

TLC: silica gel $60 \mathrm{~F}_{254}$ (Merck). Mobile phase hexane/dichloroethan/EtOH (:1:0.4) over $\mathrm{NH}_{4} \mathrm{OH}$ and $\mathrm{CHCE}_{3} / \mathrm{MEOH}$ (1:0.2) over $\mathrm{NH}_{4} \mathrm{OH}$. Spray reagent for TLC: Dragendroff's reagent.

\section{Result and Discussion}

By our investigation from total alkaloids $(0.12603 \mathrm{~g}$ of aerial parts and $0.12805 \mathrm{~g}$ roots) of $P$. harmala identified seven alkaloids, harmine., 2.2.6.6Tetramethyl-4-piperidone., Quinoline, 2.3.4trimethyl-., 1H-cyclopenta(b)

quinoline, 2.3.5.6.7.8-hexahydro-9-amino-.,

Pyridine, 2-phenoxy-4-amino-., 4-(3Propynyloxy)- quinazoline., 1H-Pyrrolo[2.1b] quinazolin-9-one, 3-hydroxy-2.3-dihydro by GC-MS (Table 1, Figure 1-2).



Figure 1.GC-MS data of Peganum harmala L 


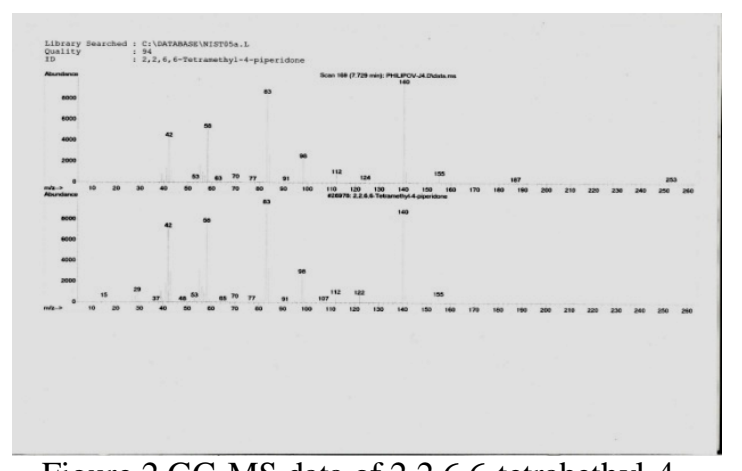

Figure 2 GC-MS data of 2.2.6.6-tetrabethyl-4piperidone

Table 1. Alkaloids from cultivated plant of $P$. harmala

\begin{tabular}{|c|c|c|c|c|c|}
\hline № & Alkaloids & $\begin{array}{c}\text { Total } \\
\text { alkaloid } \\
\mathrm{s} \\
(\%) \\
\end{array}$ & $\begin{array}{l}\text { Retentio } \\
\text { n time }\end{array}$ & $\begin{array}{c}\mathrm{M}^{+}, \text {base } \\
\text { reak. }\end{array}$ & $\begin{array}{l}\text { Formula of } \\
\text { alkaloids }\end{array}$ \\
\hline 1 & $\begin{array}{c}2.2 .6 .6- \\
\text { Tetramethy } \\
1-4- \\
\text { piperidone } \\
\end{array}$ & 10.224 & 7.729 & 143,36 & \\
\hline 2 & $\begin{array}{c}\text { Quinoline, } \\
2.3 .4- \\
\text { trimethyl- }\end{array}$ & 5.303 & 16.229 & 171,156 & \\
\hline 3 & $\begin{array}{c}1 \mathrm{H}- \\
\text { cyclopenta( } \\
\text { b) } \\
\text { quinoline, } \\
\text { 2.3.5.6.7.8- } \\
\text { hexahydro- } \\
\text { 9-amino- }\end{array}$ & 37.66 & 17.060 & 187,160 & \\
\hline 4 & $\begin{array}{c}\text { Pyridine, 2- } \\
\text { phenoxy-4- } \\
\text { amino- }\end{array}$ & 5.769 & 17.703 & 185,66 & \\
\hline 5 & $\begin{array}{c}4-(3- \\
\text { Propynylox } \\
\text { y)- } \\
\text { quinazoline }\end{array}$ & 1.419 & 17.828 & 184,130 & \\
\hline 6 & $\begin{array}{c}1 \mathrm{H}- \\
\text { Pyrrolo[2.1 } \\
\text {-b] } \\
\text { quinazolin- } \\
\text { 9-one, 3- } \\
\text { hydroxy- } \\
2.3- \\
\text { dihydro(Va } \\
\text { sicinone) } \\
\end{array}$ & 17.969 & 18.445 & 202,146 & \\
\hline 7 & Harmine & 14.819 & 20.510 & 212,169 & \\
\hline
\end{tabular}

Out of the 7 alkaloids four unknown alkaloids were isolated from $P$. harmala for the first time: 2.2.6.6-Tetramethyl-4-piperidone., Quinoline, 2.3.4-trimethyl-., Pyridine, 2phenoxy-4-amino- and 4-(3-Propynyloxy)quinazoline. The other three alkaloids: $1 \mathrm{H}-$ cyclopenta(b) quinoline, 2.3.5.6.7.8hexahydro-9-amino-., $\quad 1 \mathrm{H}-$ Pyrrolo[2.1-b] quinazolin-9-one, 3-hydroxy-2.3-dihydro and harmine were found earlier in the same species.
We determined that cultivated $P$. harmala content of the alkaloids as follows: $1 \mathrm{H}-$ cyclopenta(b) quinoline, 2.3.5.6.7.8hexahydro-9-amino-(37\%), (1H-Pyrrolo[2.1b] quinazolin-9-one, 3-hydroxy-2.3dihydro)(17.969\%), harmine(14.819\%). As it shown the contents of vasicinone and harmine in cultivated $P$. harmala were high and it gives us a wide opportunity to use in clinical practice.

\section{Conclution}

We have obtained total alkaloid from aerial parts $(33.5 \mathrm{~g})-0.12603(0.376 \%)$ and 0.12941 $\mathrm{g} \operatorname{roots}(1.5 \% /)$. High content of vasicinone and harmine from cultivated $P$. harmala indicates that the cultivation is an alternative way to obtain useful alkaloids from this plant.

\section{References}

1. Amartuvshin $\mathrm{N}$ Taxanomy of the genus Peganum L Peganaceae Van Tieghem in Mongolia Mongolian Journal of Biological Sciences vol.4(2), p-9-13, (2006)

2. Grubov V.I. Opredelitel sosudistikh rastenii Mongolii, Nauka, Leningrad. (1982)

3. Xiao, P-G. A Pictorial Encyclopedia of Chinese Medical Herbs (Japanese edition)., Chuokoron-sha, Inc. Tokyo, Japan, vol. III, p 125, (1993)

4. U. Jigaa Medocinal Plants of Mongolia used in Mongolian Traditional Medicine. Korea, Seoul, pp 343-344, 1996

5. S. Siddiqui., O.Y Khan .,B. S. Siddiqui and S. Faizi Phytochemistry vol 26, pp1548 (1987)

6. Al-Shamma A., S. Drake J. Nat.Prod.vol 44, pp 745, (1994)

7. S. Siddiqui., O.Y Khan., B. S. Siddiqui and S. Faizi Heterocycles vol 27, pp 1401 (1988)

8. Jiangshu Yixueyuan, Zhongyao Dacidian shanghai Keji chubanshe, China, vol II, pp 1757, (1977)

9. A.A Ahmed., N.A Saleh J. Nat.prod.vol 50, pp 256, (1987)

10. M. Sharaf., A.M El-Ansari Phytochemistry vol 44, pp 533 (1997) 
11. Xiao, X.-H., Qiu, G. -L., Wang, H.L., Liu, L.-S., Zheng, Y.-L., Jia, Z.-J., Deng, Z.-B Chinese journal of Pharmacology and Toxicology 2, 232, (1988)

12. Liu, Y-X. Zhongguo Shamo Zhiwuzhi, Kexue chubanshe, China, vol. 2, p-306, (1987)

13. D. Prashanth., S. John Antibacterial activity of Peganum harmala L Fitoterapia vol 70, pp 438,(1999)
14. X.H Khashimov Chem.. Prir. Soedin. 382(1971)

15. X.H Khashimov Chem.. Prir. Soedin. 456(1969)

16. X.H Khashimov Chem.. Prir. Soedin. 453(1970)

17. T. Mikdad Phytochemistry vol 30, pp 1046 (1991) 